SEFAD, 2020; (43): 59-68

e-ISSN: 2458-908X

DOI Number: https://doi.org/10.21497/sefad.755502

\title{
Trabzon Geleneksel Mutfağında Tatlılar ve Çekme Helva*
}

\author{
Dr. Berk Yilmaz \\ Karadeniz Teknik Üniversitesi, Edebiyat Fakültesi \\ Türk Dili ve Edebiyatı Bölümü \\ berkyilmaz@ktu.edu.tr
}

Öz

Toplumların yaşama biçimleri, yeme-içme alışkanlıklarını ve mutfak kültürlerini etkilemektedir. Türklerin İslamiyet'i kabulü, Orta Asya'dan Anadolu'ya gelişi, göçebelikten yerleşik yaşama geçişi gibi geçirdiği önemli değişimlerin; Türk mutfağ 1 üzerinde büyük bir etkisi vardır. Trabzon, tarihin her döneminde, ticaret yolları üzerinde olması ve Karadeniz'i Anadolu'ya bağlayan bir kapı vazifesi görmesi sebebiyle önemli bir liman kentidir. Kentin coğrafî konumu, geleneksel mutfak kültürünü de etkilemiş; Trabzon'da balık, mısır ve karalahanayla yapılan yemeklerin zengin bir çeşitliliğe sahip olmasını sağlamıştır. Trabzon mutfağında tatlılar da önemli bir yer tutmaktadır. Son yıllarda Beton helva, Laz böreği, Hamsiköy sütlacı gibi tatlılar ülke çapında tanınmıştır. Ayrıca Akçaabat ilçesinin Derecik mevkiinde sadece erkekler tarafından yapılan çekme helva da şehrin önemli tatlılarından biridir. Çalışmada, Trabzon mutfağı hakkında bilgi verilmesi, Akçaabat'a özgü çekme helvanın tanıtılması amaçlanmakta; şehrin gastronomik değerinin geliştirilmesi üzerine önerilerde bulunulmaktadır.

Anahtar Kelimeler: Mutfak kültürü, Karadeniz, Trabzon, Akçaabat, helva.

\section{Desserts and Çekme Halva in Traditional Trabzon Cuisine**}

\section{Abstract}

Ways of living in society have affected eating and drinking habits as well as cuisine culture. Turkish cuisine has been affected by accepting Islam, immigrating from Middle East to Anatolia and giving up nomadic life for transition to settled life. Since antiquity, Trabzon has always served as an important port city because of its strategic location on the crossroads of trade routes that connect the Black Sea and its vicinity to the Anatolian heartlands. Geographical position of the city has affected its traditional cuisine culture and has caused a rich variety of foods cooked with fish, corn and savoy cabbage in Trabzon. Desserts have a place in Trabzon cuisine. Desserts, such as Beton halva, Laz böreği (dessert of milk, vanilla, sugar and butter mixture on layers of pastry), "rice puding" of Hamsiköy, have been known nationwide in recent years. Also çekme halva, which is cooked by men in Derecik province in Akçaabat, is a significant dessert of the city. In this study; it is aimed to give information about Trabzon cuisine and introduce "çekme helva" specific to Akcaabat. Besides, the study gives suggestions for developing the city's gastronomic value.

Keywords: Cuisine culture, Black Sea, Trabzon, Akçaabat, halva.

\footnotetext{
* Bu makale, Prof. Dr. Kemal Üçüncü danışmanlı̆̆ında tamamlanan “Trabzon İli Geleneksel Halk Bilgisi ve Etnografyası" başlıklı doktora tezinden üretilmiştir.

** This article is part of the PhD thesis titled "Traditional Folk Knowledge and Ethnography of Trabzon Province", which was written by Berk Yılmaz under the supervision of Kemal Üçüncü. 


\section{GíRiş}

Bir toplumun mutfak kültürü, yaşama koşullarıyla doğrudan ilgilidir. Toplumların dinî inanışlar, kıtlık, göç, ticari ve sosyal etkileşim gibi unsurlarla yaşam biçimlerinin değişmesi, beslenme kültürünü de şüphesiz etkilemektedir. İnsanoğlu, ilkçağdan beri yaşamak ve çevresindekileri yaşatmak için sürekli besin kaynağı aramak zorunda kalmıştır (Güvenç, 1999, s. 204). İnsan, ilk dönemlerde avcılık toplayıcılık yapmışsa da belirli bir evrim sonucu hayvanları evcilleştirmeyi, yabani bitkileri yetiştirmeyi başarmıştır. Ateşin bulunmasıyla üretim biçiminde büyük bir değişme olmuş, buna bağlı olarak yemek türleri ve pişirme biçimleri sürekli gelişmiştir (Ögel, 1982, s. 15).

Konargöçer Türkler IX. yüzyılda tarım bölgelerinde yerleşik hayata geçmişler ve mutfak kültürleri de bu dönemde büyük gelişmeler göstermiştir. Türklerin Anadolu'ya gelip yerleşmesi modern Türk mutfağının temellerinin atılmasını sağlamıştır. Türk mutfağını oluşturan temel hususlar Orta Asya'da yaşamış olan konargöçer kültürüne ait yiyecekler, Türklerin Anadolu'ya geldikleri dönemde orada yaşayan halkların yemekleri ve Türklerin İslâmiyet'i kabulünün yemeklerine etkisidir. İslâmiyet'in kabul edilmesinden sonra Türk kültürü, Arap kültürü ile yakınlaşmış; bu durum mutfak kültürüne de yansımıştır. İslamiyet'in kabul edilmesi sonucunda bazı yiyecek, içecekler haram ve mekruh kılınmıştır. Örneğin İslamiyet'te pek makbul sayılmayan at etinin Türklerde yenildiği, kaynaklar arasinda yazılıdır (Ersoy, 2002, s. 383).

Türklerin, Orta Asya'dan günümüze yeme içme alışkanlıklarında konargöçer kültürünün etkisinin oldukça fazla olduğu görülmektedir. Orta Asya'dan bu yana, Türk mutfağında besinlerin uzun süre saklanabilmesi ve dayanıklılığını koruyabilmesi için bazı muhafaza yöntemleri kullanılmıştır. Konargöçer bir yaşam tarzı benimseyen Türkler, gerek taşıma kolaylığı gerekse bozulmadan uzun süre saklanabilmesi açısından kurutma tekniğini yaygın olarak kullanmışlardır. Sebze ve meyvelerin, yoğurdun ve etin kurutulması, çorba için yapılan tarhana ve bazı deniz ürünlerinin kurutulması bu örneklerden bazılarıdır (Dinçel, E., Bostan, K., Yalçın, S. ve Alçay Ünver, A. 2015, s. 85).

Türkler, ata yurdu olarak kabul edilen Orta Asya'nın geniş bozkırlarında uzun bir tarih diliminde büyük ölçüde hayvancılığa dayalı konargöçer bir hayat sürmüşlerdir. Bölgede karasal iklimin hüküm sürmesinden dolayı bu geniş topraklar bozkırlar ve çöllerle kaplıdır. Tabiat ve iklim özellikleri bölgenin aynı zamanda ekonomik durumunu da belirlemiştir. Şartların elverişli olmamasından dolayı geçmişte daha çok hayvancllık yapılmıştır (Vasary, 2007, s. 24-29). Bu durum belli bir bölge içinde çadırı, hayvanları ve diğer araçlarıyla yer değiştiren, sabit bir yerde daimî olarak mukim kalamayan suyun ve otlakların durumuna göre yer değiştiren konargöçer bir kültürün ortaya çıkmasına sebep olmuştur (Chailland, 2001, s. 25). Bundan dolayı her ne kadar toprağın ve iklimin tarıma elverişli olduğu yerlerde tarım yapılsa da bozkır kültürünün en önemli besin kaynağı et ve süt ürünleri olmuştur.

Türk mutfağının şekillenmesinde çevre ve iklim şartları ile dini inançların önemli bir rol oynadığının en dikkat çekici örneklerinden biri Uygurların Mani dinine girdikten sonra beslenme anlayışlarında meydana gelen değişiklikte görülmektedir. Yerleşik hayata geçen Uygurların tarımla daha çok ilgilendikleri ve tarım ürünlerine beslenmelerinde daha çok yer vermeye başladıkları bir gerçektir. Ancak Uygur mutfağındaki asıl değişimin 763 'te Bögü Kağan'ın et yerine bitki ve sebzelerin yenilmesi ile ilgili emirnamesinden sonra başladığı görülmektedir. Mani dininin beslenme anlayışından kaynaklanan bu gelişmeden sonra 
tarım faaliyetlerinin arttığ1 ve bu ürünlerin, yeni inançlarının gereği olarak Uygur mutfağında daha çok kullanılmaya başlandığı görülmektedir (Sinor, 2002, s. 449-450).

İpek ve Baharat yolları gibi milletlerarası ticaret ağları münasebetiyle ulaşım imkânının kolay olduğu bölgelere gelen ve buralarda hâkimiyet kuran Türkler, çeşitli bölgelerden gelen ürünleri tanıma ve kendi ürünlerini de tanıtma imkânına kavuşmuşlardır. Türklerin Orta Asya'da oluşturup daha sonraki nesillere intikal ettirdikleri yemek kültüründen mant1, yoğurt, ayran, kımız gibi birçok unsuru günümüze miras bıraktıkları ve bu yolla dünya mutfak kültürüne de önemli katkılar yaptıkları bilinen bir gerçektir (Mack\& Surina, 2005, p. 97). Burhan Oğuz, Anadolu Türk mutfağı hakkında bilgi verirken, mutfağın mevcut kültür birikiminden etkilendiği ve dinî inanışlarla, gelenek-göreneklerle bütünleşerek bir yekûn oluşturduğunu belirtmektedir (1976, s. 320-321). Günümüzde ise Türk mutfağının hem eski Türk geleneklerinin hem de İslamiyet'in etkisinde gösterdiği gelişim şu şekilde özetlenebilir:

Üç öğün olarak yenilen yemeklerden sonra, özellikle öğle ve akşam yemeklerinden sonra çay içilmektedir. Düğün ve benzeri tören yemekleri dışındaki toplu yemek davetleri genellikle Ramazan aylarnnda verilmektedir. Gayet zengin olan bu sofralarda, alışılmışın dışında, şakaya ve zarif fikralara hoş bakllmaktadır. Aile veya toplu yemek davetlerindeki sofralarda, bir Allah nimeti olarak görülen ekmeğin israf edilmesi veya çöpe atılması günah sayllmaktadır. Ekmek ile Türk sofra alışkanlığının bir diğer vazgeçilmezi çorbadır. O kadar ki Türk kültüründe mutluluğun tarifi, "Sıcak çorba, sıcak ev ve ağrisız vücut" şeklinde yapılmaktadır (Araz, 1986, s. 33).

Türk mutfağının gelişiminde dinî kaideler ve gelenek-göreneklerin yanı sıra Anadolu coğrafyasının iklim şartlarının da izlerinin görüldüğünü söylemek mümkündür. Burhan Oğuz'un Türk mutfağı üzerine vardığı şu genellemeler, iklimin yetiştirilen tarım ürünleri üzerinde büyük bir etkisi olduğunu ortaya koymaktadır:

- Yemek çeşidi çok fazla olup, içlerinde hamurlu yiyecekler çoğunluktadır.

- Saf et sadece muhafaza için kavrulduğunda rastlanmaktadır. Et yemeklerinin içinde daima hamur, dövülmüş buğday, bulgur, pirinç gibi ürünler bulunmaktadır.

- Bütün sebze çeşitleri kullanılmaktadır.

- Dağlarda, kırlarda kendi kendine yetişen mantar, ot ve köklerden faydalanılmakta, bunların birçoğu çiğ olarak tüketilirken bazılarının yemeği de yapılmaktadır.

- Sütten elde edilen yağlarla, hayvanın iç yağları ve kuyruk yağı, Anadolu'nun hemen her yerinde kullanılırken, zeytinyağı çoğunlukla Batı Anadolu mutfağında yer almaktadır. Zeytinyağlı soğuk yenen sebze yemeklerine Orta ve Doğu Anadolu'da yaygın olarak rastlanmamaktadir.

- Haşlamalar dışındaki sebze yemekleri ve çorbalarda bulgur yaygın kullanılmakta, Karadeniz Bölgesi yemeklerinde bulgurun yerini mısır unu almaktadır.

- Yemeklerin meyve veya meyve kurusu ile tatlandırılmasına sık rastlanmaktadır. Çoğu kez bu meyveler yağla pişirilip, yemek olarak da tüketilmektedir.

- Şeker ihtiyacı geniş ölçüde meyveler ve baldan karşılanmaktadır.

- Tercih edilen yemekler konusunda tercihe neden olabilecek lezzet, besin değeri, yemeğin yapıldığı malzemenin bol olup olmaması ve bunların elde edilme kolaylığı gibi faktörler arasında denge bulunmaktadır (Oğuz, 1976, s. 322-323).

SEFAD, 2020; (43): 59-68 


\section{Trabzon Mutfak Kültürüi}

Trabzon tarihsel süreç içerisinde dört bin yıllık bir kültürel birikimi bünyesinde barındırmaktadır. Bir imparatorluk kenti olan Trabzon, konumu itibariyle tarihinin tüm evrelerinde iklimi, yerleşime uygun yapısı, verimli toprakları, zengin orman arazileri sebebiyle tanınmıştır. Doğu Karadeniz'i asırlar boyu İç Anadolu coğrafyasına bağlayan Maçka Vadisi'nin sahilde deniz yoluyla birleşmesi, doğuda İran transit yolunun başlangıç noktası olması sebebiyle kent ekonomik, sosyal ve kültürel anlamda her dönem ön planda olmuştur. Şüphesiz kentin konumu beslenme alışkanlıklarının da şekillenmesinde etkilidir. Burada dikkat edilmesi gereken husus, coğrafyanın kentlerin kültürel dokusunda yarattığı farklılıkların beslenmede de etkili olduğudur. Bir liman kenti olması hasebiyle denizciliğin yaşamın idamesinde ana amillerden biri olması, balık üzerine zengin bir mutfağın gelişmesini sağlamıştır. Balıkla ilgili tariflere bakıldığında Karadeniz bünyesindeki tüm balıkların tava, ızgara, fırında pişirme ve buğulama başlıkları altında çeşitli tariflerle pişirildiğini görmek mümkündür. Kentte balık restoranlarının sayılarının son yirmi yılda artması bu açıdan dikkat çekicidir. Bu artışın en önemli nedeni kent sakinlerinin, avlanması, temizlenmesi ve pişirilmesine kadar olan süreçte balıkla her dönem iç içe olmasıdır.

Trabzon'un geleneksel mutfak ürünleri, ekmek ve pide çeşitleri, sütten elde edilen yiyecekler, çorbalar, hamur işinden yapılan yemekler ve börekler, tahıl ürünleri ve baklagillerle yapılan yemekler, et ve balık yemekleri, sebzelerle yapılan yemekler, tavalar, tatlılar, içecekler ve reçeller ${ }^{1}$ olarak sınıflandırılabilir. Özellikle Akçaabat köfte, kuymak, peynirli ve kavurmalı pide, karabuğday, lahana ve mısır ekmeği, peynir ve tereyağı çeşitleri; şehirde son yıllarda çekilen televizyon dizileri ve filmlerle, şehre gelen turist gruplarıla ve sosyal medya ağlarında bahsi geçen yiyeceklerin fotoğraf/videolarının paylaşılmasıyla ülke çapında tanınmıştır.

\subsection{Trabzon Mutfağında Tatlılar}

Trabzon mutfağının önemli bir bölümünü tatlılar oluşturmaktadır. Şehrin mutfak kültüründe büyük bir yeri olan balık yemeklerinin bitiminde helva tüketilmekte; dügünlerde, cenazelerde, bayramlarda ve diğer önemli günlerde tatlı ikram edilmektedir.

Trabzon'da yapılan tatlı çeşitlerini, baklavalar ve şerbetli tatlılar, burmalı / kocaman gerdanı ${ }^{2}$, kabak tatlısı, sütlaç, pirinç burmalısı ${ }^{3}$, kabarcık tatlısı ${ }^{4}$, cirihta/zilifta/ziliftar ${ }^{5}$, irmik

\footnotetext{
${ }^{1}$ Reçel yapımında bölgede yetişen tüm meyveler kullanılmaktadır. Elma, ayva, vişne, dut, kiraz, incir, kayısı, şeftali, erik reçelleri yaygın bir şekilde yapılmaktadır. Ayrıca bölgede kızılcık, kuşburnu, karayemiş, "mora" ya da "fuska" adı verilen böğürtlen, "hanifta" denilen dağ çileği ve fındık ağaçlarının diplerinde yetişen "amofta" çileğinin reçeli de yapılmaktadır. Reçel yapımında kullanılan meyveler, ilçeler arası farklılıklar gösterebilmektedir. Arsin'de kocayemiş ve gül; Çarşıbaşı'nda patlıcan, firen muşmulası, kabak ve hurma reçelleri yapılmaktadır (Keleş, 2018, s. 306).

${ }^{2}$ Burmalı tatlısının yapılış aşamaları ve sunumu baklavayla benzerlik göstermektedir. Tatlının baklavadan tek farkı yufkaların oklavada rulo halindeyken büzülerek tepsiye halkalar halinde dizilmesidir. Yufka büzüldüğünde alınan körük görüntüsü sebebiyle "gocaman gerdanı" olarak da bilinmektedir (B. Yavuz, F. Uzunoğlu, G. Kayacı, H. Ata, kişisel iletişim, 01.06. 2019).

${ }^{3}$ Pirinç burmalısının iç harcı pirinç pilavı, kuru soğan, şeker ve kuru üzümden yapılmakta; üzerine şeker serpilerek fırınlanmaktadır (E. Kahraman, N. Yılmaz, N. Şentürk, S. Beytekin, kişisel iletişim, 27.05.2019).

${ }^{4}$ Kabarcık tatlısının yapılış aşamaları lokma tatlısına oldukça benzemektedir. Aralarında şekil yönünden küçük farklılıklar bulunmakta; bir kabarcık bir lokmadan daha büyük olarak hazırlanmaktadır (S. Öztürk, S. Yılmaz, Z. Gücesan, Z. Hisoğlu, kişisel iletişim, 24.05.2019).

${ }^{5}$ Cirihta/zilifta/ziliftar tatlısının yapılış aşamaları lokma tatlısıyla hemen hemen aynıdır. Ebat olarak bir lokma tanesinden daha büyük olan bu tatlının görünüşü kabarcık tatlısına benzemekte; isteğe bağlı olarak üzerine şeker serpilerek tüketilmektedir. Bu tatlı, Arsin'de "ziliktar" ismiyle bilinmektedir (Z. Hisoğlu, kişisel iletişim, 24.05.2019).
} 
tatlısı, momoliga ${ }^{6}$, nişasta, yufka tatlısı, ekmek tatlısı, helvalı/ yağlı ekmek, makarna tatlısı" ekmek makarnası ${ }^{8}$, zumur 9 , erik pestili olarak listelemek mümkündür. Şehrin merkezinde ve tüm ilçelerinde un ve mısır unu helvaları yapılmaktadır. Ayrıca Çarşıbaşı'nda fırın kurusu helva ve pınarlı koz helvaları ${ }^{10}$; Akçaabat'ta ise çekme helva ilçeye has özellikler göstermektedir. Maçka ilçesinde Hamsiköy mevkiinde yapılan ve yöreyle özdeşleşen Hamsiköy sütlacı ${ }^{11}$ günümüzde ülke çapında bilinen bir tatlı haline gelmiştir. Tarihi dönemlerde ise Evliya Çelebi'nin Seyahat-nâmesi'nin 7. Cildinde Trabzon'a has yemekleri ele aldıktan sonra burada yediği baklavayı anlattığı şu satırlar şehrin gastronomi tarihi açısından önemlidir:

Evvelâ bir karış kadar ince ve morca ve mücellâca ve semînce balıçakdır. Nef'i ol mertebedir kim yedi gün bir âdem tenâvül etse her gice ehline varup yedişer kere kendi balı̆̆ın ehline yidire, gâyet mukavvî ve seri'u'l-hazmdır. Ve aslâ balık râyihâsı olup tenâvül edene harâret vermez. Ve hâssası oldur kim ă̆gr hastalığına mübtelâ âdem yise biemrillâh şifâ bulur. Ve bir evde yılan ve çıyan ve akreb olsa hapsi balığının başın âteşe Yakup ol hânede dütsü etseler cümle çlyan râyihâsından helâk ola. Niçe yüz gûne nef'i ve hâssası vardur amma bunu yimek Tarabefzûn halkına mahsusdur kim kırk gûne lezzet hâsıl olur. Çorbası ve yahni ve kebâbı ve böreği ve baklavası ve çorbasının envâ'ın pişirirler. Ammâ pilaki derler bir gîne ot taşından tavalar yaparlar. İbtidâ bu hapsi balığın pâk ayırtlayup onar onar kamışa dizüp ma'denos ve kerefis ve soğan ve pırasayı pâk hûrde kıyup darçın ve fülfül-i siyâh ile halt edüp bir kat kerefis ve ma'denivâzı pilaki tavası içine döşeyüp bir kat hapsi döşeyüp ba'deĥ̂ Tarabefzûn'un âb-ı hayâta benzer su zeytûn yağın döküp germâ-nermâ âteşde bir sâ'at pişüp gîyâa nûr olup tenâvül olunsa kuvvet-i basara ve mi'ideye nâfi'dir. Hakkâ kim muhabbet edecek mấide-i Sübhân'dır kim Subhânu'l-Hallâku'l-bâkî (Çelik Şavk, 2011, s.51).

Trabzon mutfak kültüründe tatlının önemli bir konuma gelmesine en önemli katkıyı şehrin yetiştirdiği tatlı ustaları ve açtıkları gastronomi mekânları sağlamaktadır. XX. yüzyılın ilk yarısında Trabzon şehir merkezinde bulunan tatlıcılar ve pastaneler, günümüze kadar ulaşmasa da kentin kültürel bellek noktalarını oluşturmaktadır12. "Raif Usta" ismiyle

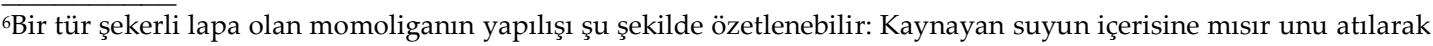
hızlıca karıştırılır. Karışım lapa halini alıp pişince başka bir tepsi içerisine konan suyun içerisine bir kaşık yardımıla yedirilerek aktarılır. Ayrı bir yerde şekerle birlikte eritilen tereyağı tepsiye aktarılan mısır lapasının aralarına yedirilir. Kat kat yığılan şekerli lapanın üzerine en son kızdırılan tereyağı gezdirilir (B. Yavuz, F. Uzunoğlu, G. Kayacı, H. Ata, kişisel iletişim, 01.06. 2019).

${ }^{7}$ Evde yapılan kesme makarna veya hazır paket makarna haşlandıktan sonra üzerine şeker dökülerek oluşturulan bir tatlı türüdür (B. Yavuz, F. Uzunoğlu, G. Kayac1, H. Ata, kişisel iletişim, 01.06. 2019).

${ }^{8}$ Bayat ekmeklerin küçük parçalara bölünerek buharla yumuşatılıp üzerine şekerli tereyağından oluşan bir karışımın dökülmesiyle hazırlanan tatlı türüdür (S. Öztürk, S. Yılmaz, Z. Gücesan, Z. Hisoğlu, kişisel iletişim, 24.05.2019).

${ }^{9}$ Bir tür ekmek tatlısı olan zumur, bayat ekmek içinden ya da yeni yoğrulup pişirilen bir ekmekten yapılmaktadır. $\mathrm{Bu}$ tarifte ekmek küçük parçalar halinde eritilen tereyağı içerisine atılıp kavrulur. Kavrulduktan sonra üzerlerine şeker dökülüp yenir (E. Kahraman, N. Yılmaz, N. Şentürk, S. Beytekin, kişisel iletişim, 27.05.2019).

${ }^{10}$ Çarşıbaşı'nda yapılan fırın kurusu ve pınarlı koz helvaları hakkında ayrıntılı bilgi için bkz. (Keleş, 2018, s. 302303).

${ }^{11}$ Hamsiköy sütlacının farkı, sütlaçların piştikten sonra küçük toprak güveçlere dökülerek fırına verilmesinden gelmektedir. Fırına verilen sütlacın üzeri katılaşan ve karamelize olan kaymaktan ötürü kızarır (Z. Nazlı, kişisel iletişim, 24.05.2019).

${ }^{12}$ Uğur Biryol'un “Bu arada sadece isimlerini anabileceğim birçok müesses var. Makrevis'ten Begioğulları'nın ben çocukken Trabzon'da işlettiği, sonra kapanan Güven Pastanesi'ni yazmazsam mesela, anılarım yakamı bırakmaz! Orada yediğim ve hâlâ birçok Hemşinlinin pastanesinde bile yapılamayan, Rus pastası 'biskot'u nasıl 
bilinen Raif Samancı, tatlı ve pasta ustalarının birinci kuşağı olarak kabul edilmekte; döneminde baklavaları ve el yapımı dondurmaları ile tanınmaktadır. "Tatlıcı Salim" olarak tanınan Salim Akgün13, "Tatlıcı Kamil" ve "Tatlıcı Kambur Mehmet" gibi ustalar, Raif Samancı'nın öğrencileri olarak Trabzon kent merkezinde tatlı etrafında zengin bir sosyal ortam oluşmasına katkı sağlamışlardır ${ }^{14}$. Bu isimlerin yanı sıra Saraçoğlu Şekerci Remzi Bey ${ }^{15}$, Trabzon ve çevresindeki illerin en büyük şekercisi olarak uzun yıllar kent merkezinde hizmet vermiştir.

XX. yüzyılın ikinci yarısında açılan ve günümüze kadar gelen, Trabzon kent kültürünün önemli gastronomi durakları olan tatlı ve pasta mekânlarının başında Beton Helva ${ }^{16}$, Selim Pastanesi, Nejla Hanım Tatlılar1 ${ }^{17}$, Uğur Usta Hamsiköy Sütlac1 ${ }^{18}$ vb. gelmektedir. Beton Helva, dökme helvacılık alanında Trabzon sınırlarını aşarak Ankara ve İstanbul'da şubeleriyle hizmet vermektedir. Nejla Hanım Tatlıları, Laz böreğinin ülke sınırları içerisinde tanıtılmasına katkı sağlamakta; farklı şehirlerdeki pek çok konumda tatlılarının satışını yapmaktadır. Hamsiköy sütlacı, Uğur Usta markası altında pek çok şehirde satılmaktadır. Bu isimlerin yanı sıra Seyyare Sungur ve üç kız kardeşi tarafından kurulan Fındık Ocağ ${ }^{19}$ firması, Trabzon'da yetişen fındıklarla el yapımı çikolatalar, şekersiz tatlılar ve fındık ezmeleri üretmekte; bu ürünleri kendi firmalarının internet sitesinde satışa sunarak son dönemlerde adını şehir dışında da duyurmaya başlamaktadır.

Trabzon kent merkezinin yanı sıra Akçaabat da tatlıcılık açısından önemli bir merkezdir. Özellikle dökme helvacılık alanında Akçaabat birden çok köklü markaya ev sahipliği yapmaktadır. 1870 yılından beri Gerigelmez ailesi tarafından yapılan un helvası, ilçeyle adeta özdeşleşmiştir20. Helvacı İbrahim, Helvacıoğlu ve Trabzon Döküm Helva önemli markalar arasında yer almaktadır. İlçenin en eski pastanesi olan Damla Pastanesi'nin ${ }^{21}$ ürünlerini Trabzon'un farklı noktalarında bulmak mümkündür.

unutabilirim?" (2016, s. 53) sözleriyle andığı Güven Pastanesi bugün hizmet vermemektedir; ancak şehrin mutfak kültüründe önemli bir yeri olduğu anlaşılmaktadır.

131923 yılında açlan ve Trabzon'un ilk pastanesi olarak kabul edilen Tatlıcı Salim, günümüzde Selim Pastanesi adıyla Ortahisar ilçesi Gazipaşa Caddesi'nde hizmet vermektedir. Ayrıntılı bilgi için bkz. https://www.karadenizgazete.com.tr/karadeniz/trabzon/dede-mirasna-sahip-ckyoruz/170298 (Erişim tarihi: 04.03.2020)

${ }^{14}$ Raif Samancı, pastanesi ve yetiştirdiği tatlı ustaları hakkında ayrıntılı bilgi için bkz. http://www.kuzeyekspres.com.tr/tatlici-raif-16418yy.htm (Erişim tarihi:04.03.2020)

15 Remzi Bey hakkında ayrıntılı bilgi için bkz. http://www.kuzeyekspres.com.tr/sekerci-remzi-ve-salim-aga16449yy.htm (Erişim tarihi: 04.03.2020)

${ }^{16}$ Beton Helva hakkında ayrıntılı bilgi için bkz. https://betonhelva.com/gizli-tarif-ustasi/ (Erişim tarihi: 04.03.2020)

${ }^{17}$ Nejla Hanım Tatlıları ve kurucusu Necla Keresteci hakkında ayrıntılı bilgi için bkz. https://www.haberler.com/trabzon-dan-bir-kadin-girisimci-hikayesi-2127763-haberi/ (Erişim tarihi: 04.03.2020)

18 İşletmenin kurucusu Uğur Alkurt, Japonya'nın süt reçelini Doğu Karadeniz'e has lezzetler olan çay, fındık ve karayemiş meyvesiyle birleştirerek ortaya özgün ve yurt dışından talep gören bir ürün çıkarmıştır. Ayrıca Hamsiköy sütlacının Japonya'da tanıtımı üzerine çalışmalar yapmaktadır. Ayrıntılı bilgi için bkz. https://www.pazar53.com/hamsikoy-sutlaci-japonya-yolunda-35841h.htm, https://yemek.com/japon-sut-recelitarifini-kesfeden-adam/ (Erişim tarihi: 06.03.2020)

19 Fındık Ocağı hakkında ayrıntılı bilgi için bkz. https://www.haber61.net/trabzon/trabzon-da-findikla-degisenhayatlar-h289773.html (Erişim tarihi: 04.03.2020)

20 Gerigelmez ailesinin helvaları, günümüzde "Helvacı İbrahim" ve "Helvacıŏglu” markası altında satılmaktadır. Ayrıntılı bilgi için bkz. http://www.akcaabatinsesi.com/helvaci-ibrahim-in-acilisi-muhtesem-oldu-2959h.htm (Erişim tarihi: 06.03.2020)

${ }^{21}$ Damla Pastanesi'ne ait internet sitesinde firmanın 1970 yılında, ailenin babası Mehmet Yılmaz tarafından Akçaaabat'ın Lise Caddesinde Menekşe Pastanesi olarak hizmete başladığı belirtilmektedir. Ayrıntılı bilgi için bkz. http://www.damlapasta.com/ (Erişim tarihi: 04.03.2020) 


\subsection{1.Çekme Helva}

Çekme helva, Trabzon'da yalnızca Akçaabat ilçesi Derecik mevkiinde yapılması açısından müstesna bir tatlıdır. Yılın her döneminde yapılabilen bu helvaya, Ramazan ayında, bayramlarda ve düğünlerde daha çok ilgi gösterilmektedir. Yapılış aşamaları ve yapılışı esnasında oluşturduğu kültürel ortam sebebiyle, ilçeye özgü un helvasından farklılık göstermektedir. Görünüş olarak pişmaniyeye benzeyen bu tatlıyı özel kılan bir başka özellik ise yapım aşamasında yoğun işçilik ve kas gücü gerektirdiğinden erkekler tarafından kalabalık bir ekibe ihtiyaç duyulmasıdır.

Çekme helvanın yapımı esnasında en az dört beş erkek birlikte çalışmaktadır. Bu çalışma ortamı, maddî bir tüketim nesnesi helvayı üretmesinin yanı sıra bulunduğu ortamda meydana gelen sosyal çevreyi de düzenlemesi açısından dikkate değerdir. Genellikle süreci iyi bilen deneyimli bir büyük tarafından yönlendirilen yapım sürecinde yetişkinler, köy seyirlik oyunlarını andıran manili, atma türkülü eğlenceler tertip eder. İmalat esnasında çalışanlar, helvanın yoğrulma ve tellenmesinde uygulanan fiziksel güce, bu işlemler sırasında oluşan çeşitli aksaklıklara dair birbirlerine çeşitli şakalar yapmakta; daha önce helva yapımına tanıklık eden kişiler bu olaya ilişkin anılarını dile getirmektedir. Helva yapımı esnasında gerçekleştirilen bu sohbetler, anlatılan fikralar, yapılan şakalar çekme helvayla ilişkili bir sözlü kültür ortamı yaratmaktadır²2. Ayrıca çalışan kişilerin yanında bulunan ve üretim sürecini gözlemleyen bir sonraki kuşak, bir usta çırak ilişkisi şeklinde gerçekleşen bir eğitim sürecine de tanıklık etmektedir.

Çekme helvanın yapımı şu şekildedir:

Bir tencere içerisine konan şeker üzerine şekeri yüzleyecek kadar su konur. Burada şekerin miktarı yaklaşık $2,5 \mathrm{~kg}$ olmalıdır. Aksi takdirde helvanın çekim işlemi zor olur. Şekerli su ocă̆ın üstüne konur ve karıştırılmaya başlanır. Su kanayıp buharlaşmaya başlayınca şeker karamelize olmaya başlar ve rengi kahverengiye doğru esmerleşir. Burada şerbetin içine bir miktar limon suyu ilave edilir. Limon suyu şerbetin sertleşmesini ve bir arada durmasın sağlayacaktır. Çok koyulursa helva çok sert olacağından çekmesi çok zor olacaktır. Bu sebepten ölçüsünün iyi bilinmesi gerekir. Şerbet iyice ağdalı bir kıvama geldiğinde altı kapatılır ve büyük bir sini, tepsi veya mermer bir zemin üzerine dökülerek soğumaya bırakılır. Ayrı bir geniş tepside beyaz un kavrulur. Soğuyan karamelize şeker bulunduğu tepsi üzerinde soğuyunca donar. Bu donmuş macunu çıkarmak için helvayı yapan kişiler tepsinin etrafinda yuvarlak bir halka oluşturur. Bir başka kişi de elinde bir kâse tereyağı tutarak tepsinin etrafinı yağlar. Ayrıca çalışan kişiler de ellerini bu yağla yağlar. Parmak uçlarıla ittirerek macunun tepsinin ortasına toplanması için gayret edilir. Sonunda ortaya macundan büyük bir top meydana gelir. Bu top elden ele gezdirilerek elde yoğrulmaya devam edilir. Macun bu esnada halen sicak olduğundan bir kişinin uzun süre elinde tutması imkânsızdır. Bu yüzden çalışan herkes elden ele gezdirerek macun topunu biraz çekip biraz katlayarak durmaksızın yoğurur. Tepsiye yapışıp kalan macun varsa bu da tepsiye sıcak su dökülüp yumuşatılarak alınır. Yoğurma işlemi bittikten sonra macun iyice uzatılarak büyükçe bir tekerlek oluşturulur. Bu tekerlek

\footnotetext{
22 “Helva yoğrulurken ufak tefek yaralanmalar olabilir bazen. Bunlara güler geçer, sonra bir daha helva yaptığımızda anlatırız. Şakalar, fıkralar da genelde bu şekilde olur. Bazen sohbet ederiz çocukken falan babamızla amcamızla yaptığımız helvaları anlatırız. İşte bize o zaman çocukken yani, sevelim helvayı heves edelim diye fıkra anlatır güldürürlerdi. Dedem böyle tekerleme, mani gibi bir şeyler söylerdi ama hiç aklımda değil şimdi. Biz de şimdi helva yaparken yanımızda genç, çocuk varsa heves etsinler diye bunları anlatırız. Yani bize göre yapması zevkli helvanın ama işte çocukların da hoşuna gitsin diye diyoruz" (Ş. Ayaz, kişisel iletişim, 03.06.2019).
}

SEFAD, 2020; (43): 59-68 
kavrulmuş unla dolu tepsi içerisine yerleştirilir. Herkes yine halka şeklinde tepsi etrafina dizilir. Macun unla karıştırılıp çekilmeye başlanır. Macun yapışkan olduğundan uzun süren bu işlem süresince una yapışır. Zor ve kol kuvveti gerektiren bu işlemi macun iyice soğumadan yapmak gerekir. Un ve macun birleşip helva kıvamına ulaştıklarında üzerinde kalan fazla un silkinir. Tepside kalan fazla un ise sıyrilıp alınır. Bu işlemden sonra geriye hazırlanan helvanın tellendirmesi kalır. Helva havaya kaldırllıp pişmaniye benzeri tellendirilerek parçalara ayrılır. İyice soğuduğu için artık yenmeye hazır hale gelmiştir (Ş. Ayaz, kişisel iletişim, 03.06.2019).

Akçaabat'ın Derecik mevkiinde yapılan çekme helvanın, coğrafî işareti bulunan Kastamonu çekme helvasından farkı, tel tel görünüşündedir. Ticari bir değeri bulunan Kastamonu çekme helvası²3, presleme yoluyla sıkıştırılıp küp, silindir, baklava dilimi gibi şekillere ayrılarak satılmaktadır. Akçaabat çekme helvasının henüz ekonomik bir değeri olmamakla birlikte; yarattığı sözlü kültür ortamı, yapılış esnasında nesilleri bir araya getirmesi gibi özellikleriyle Trabzon geleneksel mutfağında önemli bir yer tutmaktadır.

\section{SONUÇ}

Organik bir süreç olan beslenme aynı zamanda kültürel bir olgu olması nedeniyle her coğrafyada, kültürde farklılık gösterir. Tarihsel süreç içerisinde farklı kültür ve medeniyet daireleriyle temasa geçen milletler farklı unsurları bünyelerine dâhil ederler. Mutfak ve beslenme kültürü bu kültürel etkileşimin en hassas ve yüksek seviyede yaşandığı alanlardan biridir. Ticaret, göç, savaş vb. pek çok unsurun neden olduğu toplumların büyük topluluklar halinde bir yerden başka bir yere taşınması, insanların elbette gittikleri yeni yerde mevcut beslenme alışkanlıklarını sürdürmek istemeleri gibi yeni geldikleri yerin alışkanlıklarını da denemelerine fırsat sağlayacaktır. Türk kültürü, yayıldığı yirmi beş milyon kilometrekarelik geniş coğrafî alan düşünüldügüünde bu etkileşimin belki de dünyadaki en önde gelen örneklerini sergilemektedir. Tarihte farklı dönemlerde Asya, Avrupa ve Afrika kıtalarının büyük bir bölümünde hâkimiyet sağlayan Türklerin, lingua Franca'nın Türkçe olduğu bir dönem ve coğrafyada mevcut mutfak kültürlerinin de beslenme alışkanlıklarını şekillendirdiğini söylemek yanlış olmaz.

Trabzon son yıllarda Beton Helva, Laz böreği, Hamsiköy sütlacı, Akçaabat köftesi gibi tüm ülkeye mal olmuş tatlarla ön plana çıkmaktadır. Akçaabat ilçesi bu anlamda kentin en uğrak gastronomi noktalarından birini oluşturmaktadır. Şehrin geleneksel mutfak ürünlerinin ar-ge çalışmalarının yapılarak tüm dünyaya tanıtılması ve birer marka haline getirilebilmesi için günümüz teknoloji çağında imkânlar müsaittir. Henüz ticarî bir değeri olmayan, ancak yörenin tatlı kültüründe önemli bir yeri bulunan Akçaabat çekme helvanın tat, sunum gibi hususlarda geliştirilmesi, tescil edilmesi, paket halinde satışa hazırlanarak tanıtımlarla ülke çapında bilinir hale gelmesi şehrin mutfak kültürünü geliştirecek ve marka değerine katkı sağlayacaktır.

${ }^{23}$ Kastamonu çekme helvası, Kastamonu Ticaret ve Sanayi Odası tarafından 17.10.2018 tarihinde tescil edilmiştir. Ayrıntılı bilgi için bk.: https://www.ci.gov.tr/cografi-isaretler/detay/38427 (Erişim tarihi: 19. 01. 2020) 


\section{SUMMARY}

The culinary culture of a society is directly related to living conditions. Societies' religious beliefs, famine, immigration, trade and social interaction, and the way they change their lives, undoubtedly affect the nutrition culture. Migrant settler Turks started to live in agricultural regions in the 9th century and their culinary cultures showed great developments in this period. Then, settlement in Anatolia formed the basis of the modern Turkish cuisine. The migrant settler Turks' food belongings who lived in Central Asia, culture of the people living in Anatolia when Turks came and the effect of Islam's acceptance are the main points that make up the Turkish cuisine. After the acceptance of Islam, Turkish culture has become close to Arab culture and this is reflected in the culinary culture.

Trabzon is one of the important points of Turkish culinary culture in the Anatolian area. Throughout the known history of the city, due to the fact that Trabzon was an important center of different empires, Anatolia and the Black Sea constituted an important crossroads of land and sea trade routes of the city and this has provided a rich cuisine culture. The Kipchak and Cepni tribes of Turks, who entered the north of the Black Sea while making Anatolia a homeland, fused the eating habits of the Turkish culture with those of the present peoples in and around Trabzon. Later, the city became an important sanjak for the Ottoman Empire and provided the city to meet the palatal cuisine.

It is seen that the city cuisine has a unique interpretation of the milk desserts and the important flavors of the Ottoman palace cuisine. In addition to flavors such as rice pudding, halva, sweets, baklava; there are "kocaman gerdanı", "ziliftar" etc. desserts that are distinguished by different names and techniques. These desserts have become commercial tastes consumed in daily life in the city due to the spread of rice and corn farming and consumption. In this context, many dessert shops and pastry shops were opened in city centrum and Akcaabat, which is the second city center of Trabzon and an important district center. While many of them continue their profession through the next generations as family heritage, some artisans who develop traditional tastes with new ideas brought by the modern age also serve in the food and beverage industry.

There is a dessert made only in Akcaabat district on certain days of the year. It differs from other tastes, as well as the production processes and cultural products. In Ramadan and feast days, this dessert known as "cekme halva", is made by men who come together. Due to the fact that all of the kneading, pulling and wiring processes are done manually, the production process, which requires intense arm force, requires men to work. While the residents of the neighborhood were working together during the production phase, nobody took this job as a profession. This process is generally guided by an experienced elder. Adults organize rhymes, improvised folk songs and some games during the process. Young generations who want to be involved in this entertainment watch and listen to the adults. They are also involved in the production process permitted by the elder. In this way, a fun and educational, tradition-transmitting environment similar to a non-formal masterapprentice relationship, is created. The dessert has the potential to enable investments in the field of gastronomy in the city of Trabzon.

SEFAD, 2020; (43): 59-68 


\section{KAYNAKÇA}

Araz, N. (25-30 Eylül 1986). Türk yemek geleneği. Birinci Milletlerarası Yemek Kongresi Bildirileri (s.31-33). F. Halıcı (haz.). Ankara: Kültür ve Turizm Bakanlığı Yayınları.

Arslan, D. (2018, 17 Eylül). Japonya'da yediği reçelin tarifini alamayınca formülünü keşfedip dünyaya satan Trabzonlu. Erişim adresi: https://yemek.com/japon-sut-receli-tarifinikesfeden-adam/

Biryol, U. (2016). Gurbet pastası-Hemşinliler, göç ve pastacılık. İstanbul: İletişim Yayınları.

Chailland, G. (2001). Göçebe imparatorluklar: Moğolistan'dan Tuna'ya. İstanbul: Doğan Kitapçllık.

Çelik Şavk, Ü. (2011). Sorularla Evliya Çelebi-insanlık tarihine yön veren 20 kişiden biri. Ankara: Hacettepe Üniversitesi Yayınları.

Damlanın Hikayesi. (t.y.). http://www.damlapasta.com/ Erişim tarihi: 04.03.2020

Dede mirasına sahip çkıyoruz. (23.11.2017).

Karadeniz. https://www.karadenizgazete.com.tr/karadeniz/trabzon/dede-mirasna-sahipckyoruz/170298 Erişm tarihi: 04.03.2020

Dinçel, E., Bostan, K., Yalçın, S. ve Alçay Ünver, A. (2015). Orta Asya'dan Anadolu'ya kurutulmuş gidalar. ABMYO Dergisi. 40. 83-93. Erişim adresi: https://dergipark.org.tr/tr/pub/abmyoder/issue/46669/585191.

Ersoy, Y. (2002). "Türk mutfak kültürü". Türkler Ansiklopedisi. (C. IV, s.382-396). Ankara: Yeni Türkiye Yayınları.

Güvenç, B. (1999). Insan ve kültür. Ankara: Remzi Kitabevi.

Hamsiköy sütlacı Japonya yolunda (2020, 17 Şubat). Pazar 53. https://www.pazar53.com/hamsikoy-sutlaci-japonya-yolunda-35841h.htm Erişim tarihi: 06.03.2020

Helvacı İbrahim'in açılışı muhteşem oldu. (2012, 23 Ekim). Akçaabat'm Sesi. http://www.akcaabatinsesi.com/helvaci-ibrahim-in-acilisi-muhtesem-oldu-2959h.htm Erişim tarihi: 06. 03. 2020

Hikayemiz. (t.y.). https://betonhelva.com/gizli-tarif-ustasi/ Erişim tarihi: 04.03.2020

Keleş, İ. (2018). Trabzon ili Çarşıbaşı ilçesi halk bilimi monografisi (Yüksek lisans tezi). Erişim adresi: https://tez.yok.gov.tr/UlusalTezMerkezi/tezSorguSonucYeni.jsp

Kurt, H. (2018, 4 Mart). Tatlıcı Raif!. Kuzey Ekspres. Erişim adresi: http://www.kuzeyekspres.com.tr/tatlici-raif-16418yy.htm

Kurt, H. (2018, 11 Mart). Şekerci Remzi ve Salim Aga. Kuzey Ekspres. Erişim adresi: http://www.kuzeyekspres.com.tr/sekerci-remzi-ve-salim-aga-16449yy.htm

Mack, G. R. \& Surina, A. (2005). Food Culture in Russia and Central Asia. Westport - Connecticut, United States of America: Greenwood Publishing Group.

Oğuz, B. (1976). Türkiye halkının kültür kökenleri I. İstanbul: Anadolu Aydınlanma Vakfı Yayınları.

Ögel, B. (1982). Türk mutfağının gelişimi ve Türk tarihi gelenekleri. Türk Mutfağı Sempozyumu Bildirileri (s. 15-18). Ankara: Kültür ve Turizm Bakanlığı Milli Folklor Araştırma Dairesi Yayınları.

Sinor, D. (2002). Erken İç Asya tarihi. R. Sezer (çev.). İstanbul: İletişim Yayınları.

Trabzon'da findıkla değişen hayatlar (2017, 31 Mart). Haber 61. https://www.haber61.net/trabzon/trabzon-da-findikla-degisen-hayatlar-h289773.html Erişim tarihi: 04.03.2020

Trabzon'dan bir kadın girişimci hikayesi. (2010, 29 Haziran). https://www.haberler.com/trabzondan-bir-kadin-girisimci-hikayesi-2127763-haberi/ Erişim tarihi: 04.03.2020

Türk Patent ve Marka Kurumu (2018). Kastamonu Çekme Helva. Erişim adresi: https://www.ci.gov.tr/cografi-isaretler/detay/38427

Vasary, I. (2007). Eski İç Asya'nın tarihi. İ. Doğan (çev.). İstanbul: Ötüken Neşriyat.

Yılmaz, B. (2019). Trabzon ili geleneksel halk bilgisi ve etnografyası. (Doktora tezi). Erişim adresi: https://tez.yok.gov.tr/UlusalTezMerkezi/tezSorguSonucYeni.jsp. 